\title{
New scheme to eliminate power loss of start-up resistor for low standby power consumption
}

\author{
Tung-Chin Pan ${ }^{1}$, Chun-Lung Chen ${ }^{2}$, Yu-Liang Lin ${ }^{1 a)}$, \\ and Chung-Ming Leng ${ }^{1}$ \\ ${ }^{1}$ Department of Electronic Engineering, National Taiwan University of Science and \\ Technology, No.43, Sec. 4, Keelung Rd., Da'an Dist. Taipei, Taiwan \\ 2 Department of Marine Engineering, National Taiwan Ocean University, \\ No.2, Beining Rd., Jhongjheng District, Keelung, Taiwan
}

a)D9802208@mail.ntust.edu.tw

\begin{abstract}
In the initial start-up period of power converter, there is no voltage supply from auxiliary winding to pulse-width-modulation (PWM) IC. Therefore, a typical method is connected with a start-up resistor $\left(\mathrm{R}_{\text {start }}\right)$ between bridge rectifier and IC controller for initial voltage supply. However, the $\mathrm{R}_{\text {start }}$ would continue to consume energy even if the auxiliary voltage has been set up. The proposed scheme uses depletion-type NMOS to connect with $\mathrm{R}_{\text {start }}$. The start-up mechanism can be guaranteed without any additional voltage, and naturally cut off the $\mathrm{R}_{\text {start }}$ to minimize power dissipation once the voltage of PWM IC is supplied from auxiliary winding. As a result, the outstanding standby power performance can be implemented and comply the power regulation of 5 star standards of mobile charger. Experimental results demonstrate the standby power consumption only $28.8 \mathrm{~mW}$.
\end{abstract}

Keywords: start-up resistor, standby power, depletion-type NMOS

Classification: Electron devices, circuits and modules

\section{References}

[1] Y. C. Chu, et al.: "High-efficiency high-current drive power converter IC for wearable medical devices," IEICE Electron. Express 12 (2015) 20150953 (DOI: 10.1587/elex.12.20150953).

[2] K. Takeno: "Wireless power transmission technology for mobile devices," IEICE Electron. Express 10 (2013) 20132010 (DOI: 10.1587/elex.10. 20132010).

[3] S. Xu, et al.: "Digital regulation scheme for multimode primary-side controlled flyback converter," IET Trans. Power Electron. 9 (2016) 782 (DOI: 10.1049/ iet-pel.2015.0025).

[4] W. Nie, et al.: "A simple cost-effective PSR LED driver without auxiliary winding," IEICE Electron. Express 10 (2013) 20130756 (DOI: 10.1587/elex. 10.20130756).

[5] C. M. Leng, et al.: "A simple circuit to remove X-cap bleeder resistor for reducing standby power consumption," IEICE Electron. Express 13 (2016) 20160174 (DOI: 10.1587/elex.13.20160174). 
[6] NXP Semiconductors, Inc.: SSL2108X Datasheet (2013) http://www.nxp.com/ documents/data_sheet/SSL21081T_2T_3T_4T.pdf.

[7] Texas Instruments, Inc.: UCC2871X Datasheet (2012) http://www.ti.com/lit/ds/ symlink/ucc28711.pdf.

[8] Fairchild Semiconductor, Inc.: FSB-series Datasheet (2013) https://www. fairchildsemi.com/datasheets/FS/FSB117H.pdf.

[9] https://en.wikipedia.org/wiki/No_load_power.

[10] F. J. Leu: U.S. Patent 5812385 A (1998).

\section{Introduction}

The AC-DC power converter [1,2] is used in a lot of applications includes charger for mobile phone, adaptor for notebook computer and many consumer electronics, etc. By AC-DC power converter, the $\mathrm{AC}$ is converted into DC to supply energy for load. A typical AC-DC converter is controlled by PWM IC. Many start-up mechanisms are employed to create start-up power rail for PWM IC. A common method is using start-up resistor. Firstly, as shown in Fig. 1(a) [3], the AC input voltage is rectified by a bridge rectifier and the start-up resistor is connected with the line source and $\mathrm{V}_{\mathrm{CC}}$ pin of PWM IC. After the first stable switching, the voltage supply comes from auxiliary winding. Another start-up scheme is shown in Fig. 1(b) [4], it is not supplied from auxiliary winding. The start-up resistor always transfers voltage supply for control chip. However, using start-up resistor would continue consuming power in whole operation duration. This power dissipation also slightly effect the efficiency, especially in light load or standby power condition [5]. Furthermore, due to the progress of manufacture technology, the ultrahigh voltage process can be embedded into IC as shown in Fig. 1(c). The PWM IC directly connects with line source, which is able to sustain from $600 \mathrm{~V}$ to $700 \mathrm{~V}[6,7,8]$. Then, the embedded ultrahigh voltage process of PWM IC regulates the line voltage to step down for supplying power to IC. However, the cost of PWM IC adopts ultrahigh voltage process is very expensive. The static power consumption still exists because of the large voltage drop between line source and $\mathrm{V}_{\mathrm{CC}}$ pin of IC. Moreover, the no-load power consumption in 5 star standards of mobile charger is under $30 \mathrm{~mW}$ [9]. In low rating power converter, the standby power loss from start-up resistor is a major proportion. For complying with the power regulations, we need some solutions to eliminate the power loss of start-up resistor with a simple and low cost scheme once the auxiliary voltage has been successful built particularly in low power application.

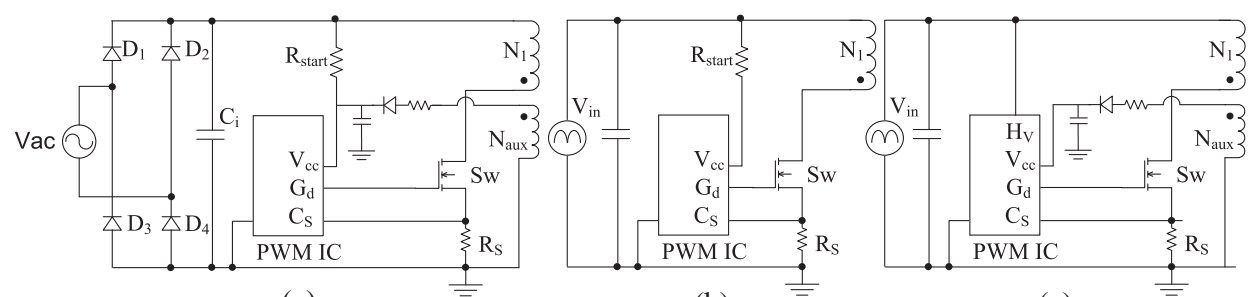

(b)

(c)

Fig. 1. PWM IC start-up mechanisms: (a) Start-up resistor and auxiliary winding. (b) Start-up with resistor. (c) Embedded high-voltage start-up pin. 


\section{Scheme description}

Fig. 2 shows the proposed scheme, which uses depletion-type NMOS to remove start-up resistor. The whole scheme is composed of one start-up resistor $\left(\mathrm{R}_{\text {start }}\right)$, one depletion-type $\operatorname{NMOS}\left(\mathrm{Q}_{1}\right)$, one bipolar device $\left(\mathrm{Q}_{2}\right)$, two current limit resistor $\left(\mathrm{R}_{1}, \mathrm{R}_{2}\right)$, two diode $\left(\mathrm{D}_{1}, \mathrm{D}_{2}\right)$, two hold-up capacitor $\left(\mathrm{C}_{1}, \mathrm{C}_{2}\right)$, one auxiliary winding $\left(\mathrm{N}_{\mathrm{aux}}\right)$, one primary winding $\left(\mathrm{N}_{1}\right)$, one main switch $\left(\mathrm{S}_{\mathrm{W}}\right)$, one current sensor resistor $\left(\mathrm{R}_{\mathrm{S}}\right)$, and one PWM IC.

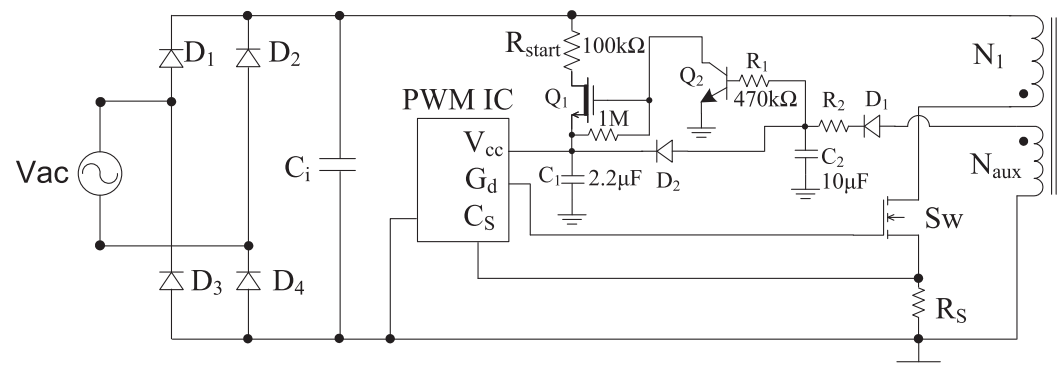

Fig. 2. Proposed remove start-up resistor scheme.

The example and value of start-up resistor can be determined as equation (1). The power dissipation of start-up resistor is calculated as equation (2).

$$
\begin{gathered}
R_{\text {start }} \leq \frac{\sqrt{2} * V_{a c_{-} r m s_{-} \min }-V_{\text {th_ic }}}{I_{\text {ic }}}=\frac{\sqrt{2} * 90 \mathrm{~V}-13 \mathrm{~V}}{1 \mathrm{~mA}} \cong 114 \mathrm{k} \Omega \\
P_{R_{\text {start }}}=\frac{V_{\text {ac_rms }}^{2}}{R_{\text {start }}}=\frac{230^{2} \mathrm{~V}_{\mathrm{rms}}}{100 \mathrm{k} \Omega} \cong 529 \mathrm{~mW}
\end{gathered}
$$

where $\mathrm{V}_{\text {ac_rms_min }}$ is the minimum of root mean square of $\mathrm{AC}$ input voltage. $\mathrm{V}_{\text {th_ic }}$ is the turn-on threshold voltage of PWM IC. $\mathrm{I}_{\mathrm{ic}}$ is the driving current of IC.

As shown in Fig. 3(a), the initial start-up mechanism is supplied from $\mathrm{R}_{\text {start }}$ and $\mathrm{Q}_{1}$ (normally closed) to charge $\mathrm{C}_{1}$ for supplying PWM IC. The IC initial sink little current (typically $20 \mathrm{uA}$ ), when the $\mathrm{V}_{\mathrm{C} 1}$ reaches $\mathrm{V}_{\text {th_ic }}(13 \mathrm{~V})$, IC starts to pulse (duty) and its consumption increases (typically $1 \mathrm{~mA}$ ). Owing to the main switch $\left(\mathrm{S}_{\mathrm{w}}\right)$ is controlled by duty therefore $\mathrm{V}_{\mathrm{C} 2}$ is build up gradually. At the same time, the peripheral components $\left(\mathrm{Q}_{2}, \mathrm{D}_{2}, \mathrm{D}_{1}\right)$ are not activated due to the shortage of adequate $\mathrm{V}_{\mathrm{C} 2}$.

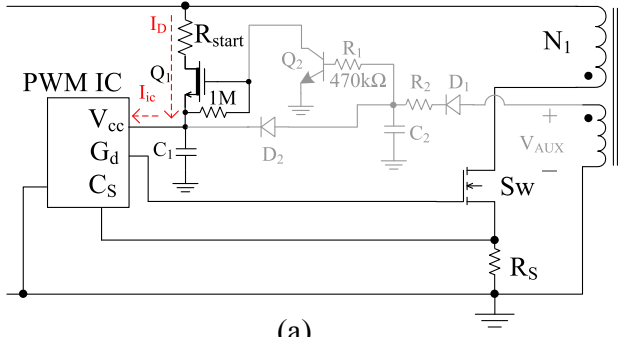

(a)

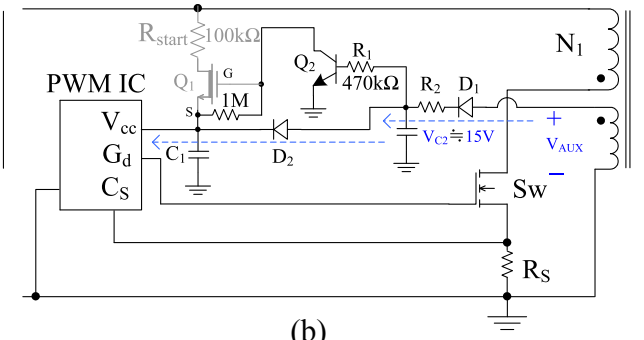

(b)

Fig. 3. Start-up mechanism of proposed scheme. 
reverse-bias voltage $\left(\mathrm{V}_{\mathrm{GS}} \geqq-5 \mathrm{~V}\right)$ would turn off $\mathrm{Q}_{1}$, thus the $\mathrm{C}_{1}$ solely delivers energy to the IC. After about $5 \mathrm{~ms}$, the $\mathrm{V}_{\mathrm{C} 2}$ reaches $13 \mathrm{~V}$ and via diode takes over for supply the IC. As long as the $\mathrm{V}_{\mathrm{C} 1}$ do not drops below a level called under voltage lock-out (UVLO), (typically $8 \mathrm{~V}$ ), the IC will continue to send duty and the whole start-up mechanism will be achieved. Finally the power loss from start-up resistor is removed in normal operation interval as shown in Fig. 3(b).

The $\mathrm{C}_{1}$ selection depends on the hold-up time needed from $\mathrm{C}_{1}$ supply IC until the auxiliary voltage takes over, in proposed case is:

$$
C_{1}=\frac{I T}{\Delta V}=\frac{I_{i c} * t_{\text {hold_up }}}{V_{\text {th_ic }}-U V L O}=\frac{1 \mathrm{~mA} * 10 \mathrm{~ms}}{13 \mathrm{~V}-8 \mathrm{~V}} \cong 2 \mu \mathrm{F}, \text { choose } 2.2 \mu \mathrm{F} .
$$

The $\mathrm{C}_{2}$ selection is depend on the ripple of $\mathrm{V}_{\mathrm{C} 2}$, in proposed case is:

$$
C_{2}=\frac{I T}{\Delta V}=\frac{I_{i c} * t_{V_{A U X}}}{V_{C 2 \_ \text {ripple }}}=\frac{1 \mathrm{~mA} * 10 \mathrm{~ms}}{1 \mathrm{~V}} \cong 10 \mu \mathrm{F} \text {, choose } 10 \mu \mathrm{F} \text {. }
$$

In proposed case, in order to compare with conventional remove start-up resistor method [10] shown as Fig. 4, therefore $\mathrm{R}_{1}$ be select as $470 \mathrm{k} \Omega$. Actually, the better design should $\mathrm{Q}_{2}$ be turned on when $\mathrm{V}_{\mathrm{C} 2}>9 \mathrm{~V}$ (UVLO + forward voltage of diode), we can replace proposed $R_{1}$ as a $9 \mathrm{~V}$ Zener diode for ensure $\mathrm{V}_{\mathrm{C} 1}>\mathrm{UVLO}$ or design the base current of $\mathrm{Q}_{2}$ is activated when $\mathrm{V}_{\mathrm{C} 2}>9 \mathrm{~V}$.

Proposed scheme looks like simple, but please consider there is no voltage can be supplied from $\mathrm{V}_{\mathrm{AUX}}$ at initial operation. If $\mathrm{Q}_{1}$ is substituted by MOSFET or transistor (normally open), then the power converter of Fig. 2 can't work in the initial start-up period without supply from power rail. Compare with Fig. 4. The initial voltage is supplied through $\mathrm{R}_{\text {start }}$ and bipolar transistor $\left(\mathrm{Q}_{1}\right)$ as Fig. 4(a). Once the auxiliary voltage $\left(\mathrm{N}_{\mathrm{AUX}}\right)$ has been established, the $\mathrm{Q}_{1}$ is turned off by $\mathrm{Q}_{2}$ as Fig. 4(b). But the power loss becomes $\mathrm{R}_{1}$ to ground. In $230 \mathrm{~V}_{\text {rms }}$ condition, the power loss from $R_{1}$ is about $230^{2} \mathrm{~V} \div 470 \mathrm{k} \Omega=112.5 \mathrm{~mW}$. This power loss can't meet the standby power regulation in 5 star standards of mobile charger (must under $30 \mathrm{~mW})$. In proposed scheme, the power loss $\left(230^{2} \mathrm{~V} \div 100 \mathrm{k} \Omega=529 \mathrm{~mW}\right)$ from $\mathrm{R}_{\text {start }}$ is completely removed. Even if considering other standby power consumptions from PWM IC, bridge rectifier, magnetic component, etc., the standby power consumption of whole power converter still can meet the regulation.

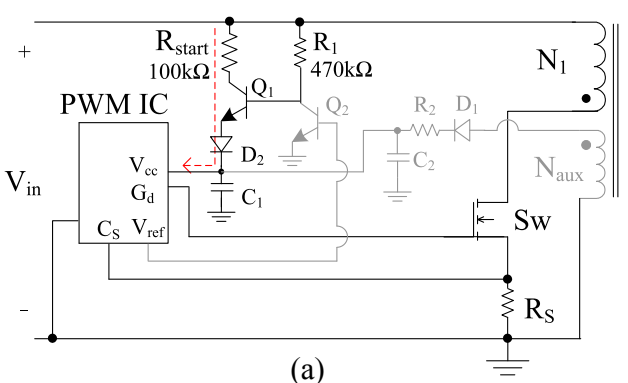

(a)

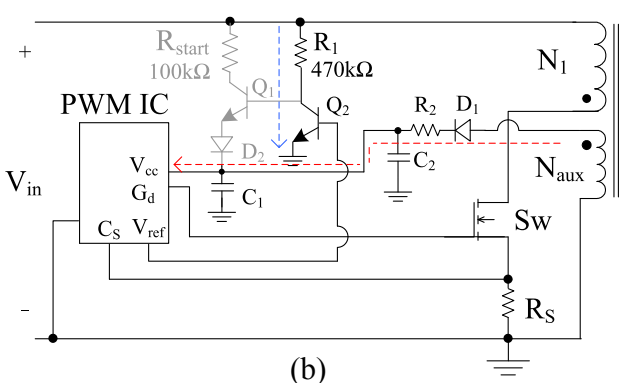

(b)

Fig. 4. Conventional remove start-up resistor method. 


\section{Experimental verification}

To verify the feasibility of the proposed remove start-up resistor scheme, a prototype converter as shown in Fig. 2 has been constructed in the laboratory. The measured experimental results with the following parameters:

1) AC input voltage: $230 \mathrm{~V}_{\text {rms }}$

2) Start-up resistor: $100 \mathrm{k} \Omega$

3) Hold-up capacitor $\left(\mathrm{C}_{1}\right),\left(\mathrm{C}_{2}\right): 2.2 \mu \mathrm{F}, 10 \mu \mathrm{F}$

4) PWM IC turn-on threshold voltage: $13 \mathrm{~V}$

5) Rated output power of AC-DC converter: $7.5 \mathrm{~W}$ (focus for mobile phone charger application)

Fig. 5 shows the power-on sequence from initial voltage to the steady value of $15 \mathrm{~V}$. After the power-on sequence, PWM IC is supplied from the auxiliary winding (actually the voltage of auxiliary winding $\mathrm{V}_{\mathrm{AUX}}$ is approximate rectangle waveform of positive and negative half-cycle, and converts by diode $\mathrm{D}_{1}$ to direct current and keeps about $15 \mathrm{~V}$ in hold-up capacitor $\mathrm{C}_{2}$ ). The waveforms show the voltage of $\mathrm{V}_{\mathrm{C} 2}$ is from $0 \mathrm{~V}$ rising to $15 \mathrm{~V}$. The voltage in gate pin of depletion-type $\operatorname{NMOS}\left(\mathrm{Q}_{1}\right)$ falls to $0 \mathrm{~V}$ and the voltage in source pin of $\mathrm{Q}_{1}$ rises up to $15 \mathrm{~V}$. Therefore, the voltage $\left(\mathrm{V}_{\mathrm{GS}}\right)$ of $\mathrm{Q}_{1}$ is $-15 \mathrm{~V}$ and then more ensure to be turned off. The startup time is below $25 \mathrm{~ms}$ due to the start-up resistor in proposed scheme is only $100 \mathrm{k} \Omega$, which can supply higher current than traditional start-up resistor $(1 \mathrm{M} \Omega)$. This concludes the proposed scheme to be particularly suitable for quick start of the charger application. After power start-up mechanism, the AC-DC converter is fully functional and regulated, even if the start-up resistor is already disconnected. On the other hand, the depletion-type NMOS is completely turned off. Consequently, there is no any power loss or leakage current from the start-up resistor $\left(\mathrm{R}_{\text {start }}\right.$ loss $230^{2} \mathrm{~V} \div 100 \mathrm{k} \Omega=529 \mathrm{~mW}$ is completely removed). In the end, the overall efficiency is slightly improved. From views on the overall result, the standby power consumption of whole power converter is only $28.8 \mathrm{~mW}$ (when rated output power is $7.5 \mathrm{~W}$ ) in $230 \mathrm{Vrms}$ condition as captured in Fig. 6 . And this power consumption can comply the standby power regulation in 5 star standards of mobile charger.

Summarize the proposed technique for remove the start-up resistor is quite simple and low cost (depletion-type NMOS cost below USD\$ 0.02). The further specification of depletion-type NMOS is listed in Table I.

Table I. Key parameters of the proposed depletion-type NMOS

\begin{tabular}{c|c}
\hline $\mathrm{V}_{\mathrm{DS} \_ \text {max }}=600 \mathrm{~V}$ & $\mathrm{I}_{\mathrm{D} \_ \text {max }}=18.5 \mathrm{~mA}$ \\
\hline $\mathrm{V}_{\mathrm{DG} \_ \text {max }}=600 \mathrm{~V}$ & $\mathrm{I}_{\mathrm{D} \_ \text {peak }}=74 \mathrm{~mA}$ \\
\hline $\mathrm{V}_{\mathrm{GS} \_\max }= \pm 20 \mathrm{~V}$ & $\mathrm{~V}_{\mathrm{GS} \text { _breakdown }}=-5 \mathrm{~V}$ \\
\hline $\mathrm{C}_{\mathrm{iss}}=9.4 \mathrm{pF}$ & $\mathrm{R}_{\mathrm{ds} \_ \text {on }}=600 \Omega$ \\
\hline
\end{tabular}




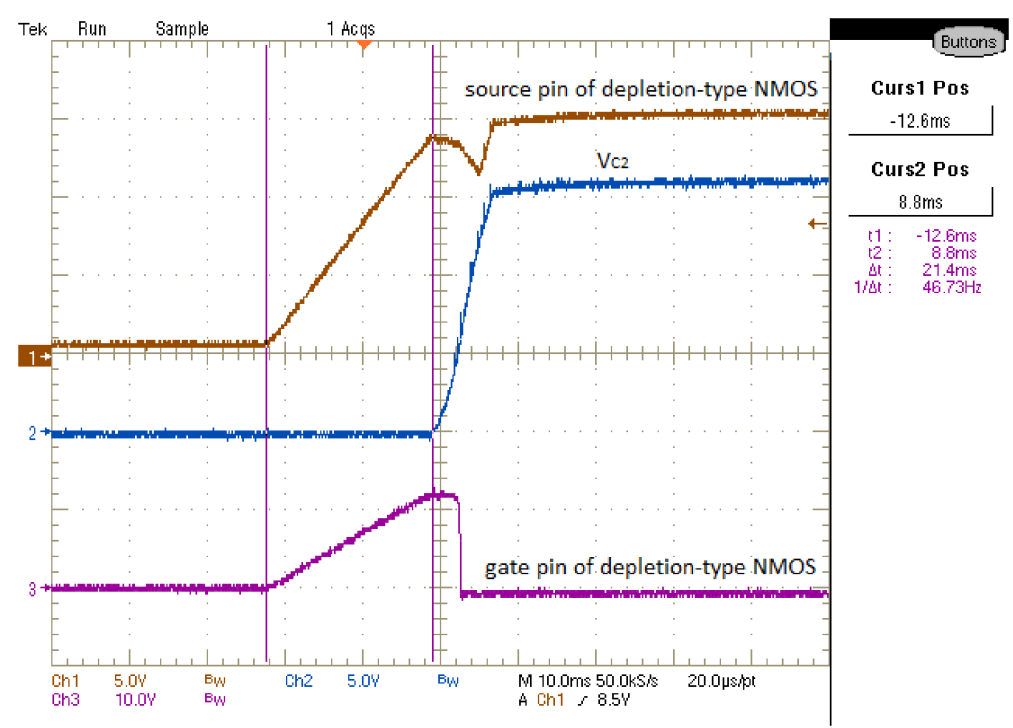

Fig. 5. The waveforms of power-on sequence.

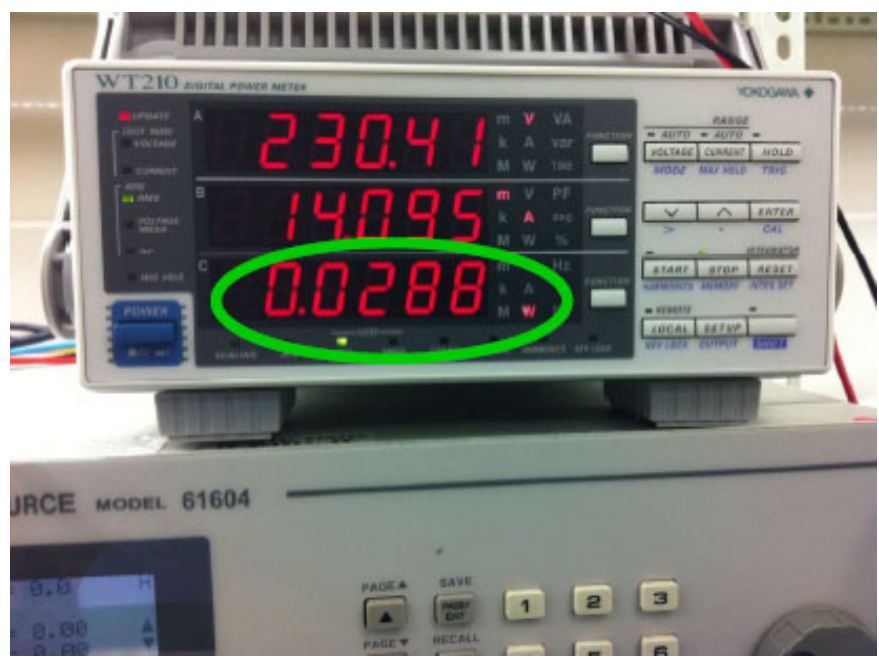

Fig. 6. Converter measurement result with extreme low standby power.

\section{Conclusion}

Using depletion-type NMOS technique can ensure the initial voltage supply by start-up resistor during the power-on period. Owing to the depletion-type NMOS is normally turned on without any additional auxiliary voltage. Besides, by proposed scheme, the depletion-type NMOS can be fully shut down to eliminate power loss from start-up resistor for meet the standby power regulation, especially in no load or standby power condition when the auxiliary voltage has been successfully built. Experimental results show that the standby power consumption is only $28.8 \mathrm{~mW}$. This result can meet the 5 star standards of mobile charger regulation with a simple and low cost solution.

\section{Acknowledgment}

The financial support is from project (MOST 104-2221-E-011-172-MY3) of professor Rong-Jong Wai. 